\title{
Effects of Intravenous Agent Used on Oxygen Desaturation during Suxamethonium Apnoea
}

\author{
George Tweneboah ${ }^{1}$, Jane Acquaye ${ }^{2 *}$, Lorraine Sallah ${ }^{3}$, Tsiri Agbenyega ${ }^{3}$ \\ ${ }^{1}$ Department of Anesthesia, Komfo Anokye Teaching Hospital, Kumasi, Ghana \\ ${ }^{2}$ Department of Surgery, Komfo Anokye Teaching Hospital, Kumasi, Ghana \\ ${ }^{3}$ Department of Physiology, Kwame Nkrumah University of Science and Technology, Kumasi, Ghana \\ Email: ^maame.jenny@yahoo.com
}

How to cite this paper: Tweneboah, G., Acquaye, J., Sallah, L. and Agbenyega, T. (2021) Effects of Intravenous Agent Used on Oxygen Desaturation during Suxamethonium Apnoea. Open Access Library Journal, 8: e7805.

https://doi.org/10.4236/oalib.1107805

Received: July 29, 2021

Accepted: August 28, 2021

Published: August 31, 2021

Copyright (C) 2021 by author(s) and Open Access Library Inc.

This work is licensed under the Creative Commons Attribution International License (CC BY 4.0).

http://creativecommons.org/licenses/by/4.0/

\begin{abstract}
Anesthesia induction consists of pre-oxygenation, intravenous agent, muscle relaxant which causes apnea for laryngoscopy and intubation. The three commonly used intravenous agents are Ketamine, Propofol and Thiopentone. However, various views have been expressed in relation to oxygen saturation during anesthesia. The study sought to affirm the rate of oxygen desaturation during suxamethonium apnea in relation to the intravenous induction agent used. An observational research design was adopted for the study. A total of $94 \mathrm{pa}-$ tients were engaged in the study. Descriptive statistics, correlation and ANOVA were used to analyze the data. The study found that patients administered with Ketamine as an induction agent recorded the least average time for oxygen desaturation, whereas those given thiopentone recorded the highest time of oxygen desaturation. Patients who received thiopentone as an induction agent had the least induction duration, whereas those administered with Propofol recorded the longest induction duration. The study concludes that there is no significant difference in the rate of oxygen desaturation among the three intravenous agents.
\end{abstract}

\section{Subject Areas \\ Drugs \& Devices}

\section{Keywords}

Intravenous Agent, Oxygen Desaturation, Suxamethonium Apnoea, Anesthesia

\section{Introduction}

Patients undergoing general anesthesia with endotracheal intubation have to be 
given an intravenous induction agent in addition to a muscle relaxant [1]. However, the rate of oxygen desaturation with muscle relaxant has been established [2]. Meanwhile, there have been several opinions on the rate of oxygen desaturation during suxamethonium apnoea with the following induction agents: ketamine, Propofol and Thiopentone [3]. Moreover, the three intravenous induction agents are commonly used in Komfo Anokye Teaching Hospital. Therefore, there is a need to confirm the effects of ketamine, Propofol and Thiopentone on the rate of oxygen desaturation during suxamethonium apnea.

\section{Method}

It's an observational research design with independent variables of hemoglobin concentration and administration of induction agent, whereas the dependent variable was oxygen saturation.

The population of the study comprised all surgery patients admitted to department of Surgery at Komfo Anokye Teaching Hospital from $1^{\text {st }}$ April to $31^{\text {st }}$ July 2016.

A sample size of Ninety-four was used, Kirkwood and Sterne (2003) [4], this ensured statistical representation of the sample size in relation to the study population. Purposive sampling was used to sample patients from the population, aimed at obtaining clients eligible for the study.

An approved guideline and ethical clearance from Kwame Nkrumah University of Science and Technology Ethics Committee and Committee on Human Resource Publication and Ethics (CHPRE) of Komfo Anokye Teaching Hospital was obtained. Consent was sought from patients and their relatives before the study in which the consent form was read and explained in the local dialect for patients who could not read.

Selected patients had their noninvasive blood pressure checked with automated Dash 4000 monitor; manual respiratory rate count with breast watch; axillary temperature checked with mercury thermometer; height and weight with body mass index taken with a tape meter and standing scale respectively. Those with hemoglobin concentration checked more than 24 hours before the study, had venous blood sample taken during intravenous set up for hemoglobin concentration and blood group. The clients were then positioned on operating table. The Life Box pulse oximeter was applied to the thumb finger for continuous measure of oxygen saturation before pre-oxygenation and during induction of anesthesia. Each participant underwent routine anesthesia induction as follows: inhalation of $100 \%$ oxygen for three minutes, administration of an intravenous agent of choice by anesthetist, followed by suxamethonium $1 \mathrm{mg} / \mathrm{kg}$. The face mask was removed for laryngoscopy and intubation after fasciculation. The time between the administrations of induction agent until the end of endotracheal intubation during the apneic period was recorded against the time for each participant for each group as Table 1.

In cases where patient desaturated to $92 \%$ before a successful intubation, then 
Table 1. Times for recording apneic period for the participants.

\begin{tabular}{ccc}
\hline $\begin{array}{c}\text { Oxygen } \\
\text { saturation } \%\end{array}$ & $\begin{array}{c}\text { Time period in } \\
\text { milliseconds } \mathrm{T}\end{array}$ & $\begin{array}{c}\text { Time period in milliseconds } \\
\mathrm{T}_{1} \text { (second attempt) }\end{array}$ \\
\hline 100 & $\mathrm{~T} 100$ & $\mathrm{~T}_{1} 100$ \\
99 & $\mathrm{~T} 99$ & $\mathrm{~T}_{1} 99$ \\
98 & $\mathrm{~T} 98$ & $\mathrm{~T}_{1} 98$ \\
97 & $\mathrm{~T} 97$ & $\mathrm{~T}_{1} 97$ \\
96 & $\mathrm{~T} 96$ & $\mathrm{~T}_{1} 96$ \\
95 & $\mathrm{~T} 95$ & $\mathrm{~T}_{1} 95$ \\
94 & $\mathrm{~T} 94$ & $\mathrm{~T}_{1} 94$ \\
93 & $\mathrm{~T} 93$ & $\mathrm{~T}_{1} 93$ \\
92 & $\mathrm{~T} 92$ & $\mathrm{~T}_{1} 92$ \\
\hline
\end{tabular}

Source: Field data (2016).

patient was ventilated to raise the oxygen saturation to $100 \%$ before the next attempt of intubation and the values for the repeated time was recorded as $T_{1}$ per table A with respect to the changes in oxygen saturation. The induction agent used, duration of induction, diagnosis, type of surgery and premedication used were recorded.

The data were processed using Microsoft Excel 2010 Professional Edition.

Descriptive statistics such as means, standard deviation as well as inferential statistics such as correlation and one-way analysis of variance were used to analyse data collected. An error margin of 0.05 was used for all inferential analyses.

\section{Results}

Figure 1 presents result of preoperative fitness of patients presented for surgery based on the classification of American Society of Anaesthesiology (ASA) [5], with 55.3\% (ASAIE + ASAIIE) being emergency and $44.7 \%$ being elective.

ASA I-Normal healthy patient: $39.4 \%$;

ASA IE-Normal healthy patient who required emergency surgery: $14.9 \%$;

ASA II-Patient with mild systemic disease; no functional limitation: 5.3\%;

ASA IIE-Patient with mild systemic disease who required emergency surgery: $40.4 \%$.

Table 2 shows BMI data on sample size with $68 \%$ (normal), 27.7\% (overweight) and $4.3 \%$ (obese).

Below $25 \mathrm{~kg} / \mathrm{m}^{2}$-Normal BMI;

25 - $29.9 \mathrm{~kg} / \mathrm{m}^{2}$-Overweight;

30 and plus $\mathrm{kg} / \mathrm{m}^{2}$-Obese.

Table 3 represents descriptive on duration of induction in relation to the induction agents used on sampled patients with Propofol recording the longest time of 7:02.22 and thiopentone recording the least mean time.

$\mathrm{N}$ = sample size;

Mean $=$ average time of induction. 


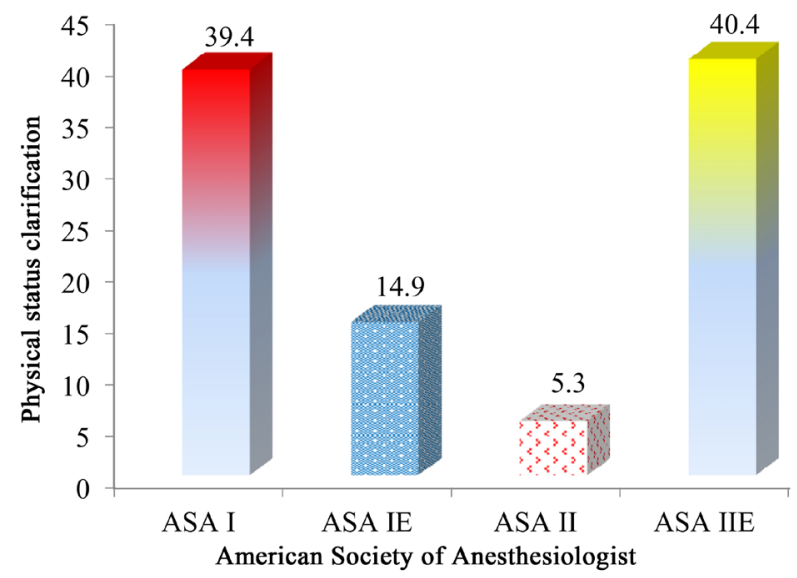

Figure 1. Percentages of preoperative physical status of the patients presented for surgery. Source: Field data (2016).

Table 2. Frequency and percentage of Body mass index of patients presented for surgery.

\begin{tabular}{ccc}
\hline BMI $\left(\mathbf{k g ~ p e r ~} \mathrm{m}^{2}\right)$ & Frequency & Percentage \\
\hline Below 25 & 64 & 68.0 \\
$25 \_29.9$ & 26 & 27.7 \\
30 and plus & 4 & 4.3 \\
Total & 94 & 100.0 \\
\hline
\end{tabular}

Source: Field data (2016).

Table 3. Duration of induction in relation to the induction agents used on patients.

\begin{tabular}{cccccc}
\hline Induction agents & $\mathbf{N}$ & $\begin{array}{c}\text { Mean } \\
(\mathrm{ms})\end{array}$ & Stdv. & $\begin{array}{r}\text { Min } \\
(\mathrm{ms})\end{array}$ & Max (ms) \\
\hline Propofol & 50 & $7: 02.22$ & $1: 14.42$ & $5: 53.02$ & $14: 49.02$ \\
Thiopentone & 19 & $6: 29.44$ & $1: 41.26$ & $5: 33: 07$ & $8: 14.07$ \\
Ketamine & 25 & $6: 49.48$ & $0: 55.12$ & $5: 27.06$ & $8: 28.00$ \\
Total & $\mathbf{9 4}$ & $\mathbf{6 : 5 2 . 2 6}$ & $\mathbf{1 : 1 6 . 4 0}$ & $5: 27.06$ & $\mathbf{1 4 : 4 9 . 0 2}$ \\
\hline
\end{tabular}

Source: Field survey (2016).

Table 4 represents post-hoc test to assess statistical of difference among the different induction agent administered to sample patients with no relation established.

Sig. value for Levene's test $=0.574$ (Levene statistic $=0.558)$

Sig. value $=$ p-value (probability value $)$ it is the actual error associated with the test $\mathrm{df}=$ degree of freedom (number of sub-categories minus one) F-statistic $=$ Anova value.

The results (Table 5) show that patients administered with ketamine as induction agent recorded the least average time for oxygen saturation $(1: 1725 \mathrm{~ms})$, whereas those given thiopentone recorded the highest $(1: 38.54 \mathrm{~ms})$ oxygen saturation. 
Table 4. One-way analysis of variance on duration of induction in relation to induction agents used.

\begin{tabular}{cccccc}
\hline Groups & Sum of squares & df & Mean squares & F & Sig. \\
\hline Between groups & $53,598,940.469$ & 2 & $26,799,470.235$ & 1.274 & 0.285 \\
Within groups & $1,914,826,868.307$ & 91 & $21,042,053.498$ & & \\
Total & $1,968,425,808.777$ & 93 & & & \\
\hline
\end{tabular}

Source: Field survey (2016).

Table 5. Descriptive mean, standard deviation, minimum and maximum time on oxygen saturation of the patients in relation to induction agents used at induction of anesthesia.

\begin{tabular}{cccccc}
\hline Induction agents & $\mathrm{N}$ & Mean $(\mathrm{ms})$ & Stdv. & Min $(\mathrm{ms})$ & Max $(\mathrm{ms})$ \\
\hline Propofol & 50 & $1: 30.34$ & $0: 57.59$ & $0: 21.02$ & $4: 08.02$ \\
Thiopentone & 19 & $1: 38.54$ & $1: 15.50$ & $0: 00.00$ & $3: 01.05$ \\
Ketamine & 25 & $1: 17.25$ & $1: 12.17$ & $0: 19.09$ & $4: 49.06$ \\
Total & $\mathbf{9 4}$ & $\mathbf{1 : 2 8 . 4 5}$ & $\mathbf{1 : 0 5 . 3 0}$ & $\mathbf{0 : 0 0 . 0 0}$ & $\mathbf{4 : 4 9 . 0 6}$ \\
\hline
\end{tabular}

Source: Field survey (2016).

$\mathrm{N}$ = sample size;

Mean $=$ Average time for oxygen saturation in minutes.

Table 6 represents a further test conducted using one-way variance showing no difference in oxygen saturation in relation to difference in induction agent used.

Sig. value for Levene's test $=0.327$ (Levene statistic $=0.160$ ).

Sig. value $=p$-value (probability value) - it is the actual error associated with the test $\mathrm{df}=$ degree of freedom (number of sub-categories minus one) F-statistic = Anova value.

\section{Discussion}

From the study, the majority of the patients were operated under emergency circumstances. This is likely to affect extensive preoperative assessment for effective airway management as described by (Lane et al., 2005) [6]. They reported that the majority of airway complications are recorded against emergency patients (Lane et al., 2005) [6]. In addition, anaesthetist may be unable to obtain the detailed medical and surgery history on emergency patients, which according to (Nimmagadda, 2001) [7] could make general anesthesia difficult in cases where patients have history of diabetes mellitus, rheumatoid arthritis or ankylosing spondylitis.

According to the World Health Organisation (2011) [8], a body mass index of between $25 \mathrm{~kg}$ per $\mathrm{m}^{2}$ and $29.9 \mathrm{~kg}$ per $\mathrm{m}^{2}$, shows that a person is overweight, and

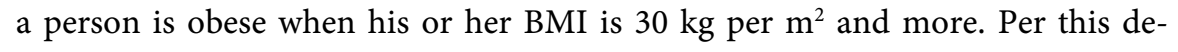
scription, the results show that $27.7 \%$ of the patients were overweight, whereas $4.3 \%$ were obese. The implication is that the majority (95.7\%) of the patients are not likely to experience difficult intubation during airway management [9]. 
Table 6. One-way analysis of variance on oxygen saturation of the patients in relation to induction agents used.

\begin{tabular}{cccccc}
\hline Groups & Sum of squares & df & Mean squares & F & Sig. \\
\hline Between groups & $19,221,186.534$ & 2 & $9,610,593.267$ & 0.617 & 0.542 \\
Within groups & $1,417,532,430.285$ & 91 & $15,577,279.454$ & & \\
Total & $1,436,753,616.819$ & 93 & & & \\
\hline
\end{tabular}

Source: Field data (2016)

The results show that patients administered with Ketamine as induction agent recorded the least average time for oxygen desaturation, whereas those given thiopentone recorded the highest duration for oxygen desaturation. There was no statistical significant relation between induction agent used and rate of oxygen desaturation. This disagrees with Lebovic et al., (1992) [3] that Ketamine used in induction of anesthesia maintains oxygen and Propofol caused desaturation in four out of ten patients in a comparative study.

The implication is that the oxygen desaturation among patients with different induction agents was similar. The results further mean that differences in the induction agents administered to patients did not cause any critical influence on oxygen desaturation.

\section{Conclusions}

The study found that patients administered with Ketamine as an induction agent recorded the least average time for oxygen desaturation, whereas those given thiopentone recorded the highest time of oxygen desaturation.

Patients who received thiopentone as an induction agent had the least induction duration, whereas those administered with Propofol recorded the longest induction duration. However, there was no significant difference among Ketamine, Propofol and Thiopentone.

\section{Limitation of the Study}

Since the study was conducted in humans, the critical desaturation point of $88 \%$ - $90 \%$ was set at $92 \%$.

Another limitation of the study was the difficulty to the researcher to obtain background information about some of the patients because of pain.

\section{Recommendation}

The study recommends that patients should be optimized for surgery instead of depending on ketamine as other studies claimed.

\section{Conflicts of Interest}

The authors declare no conflicts of interest.

\section{References}

[1] Tanoubi, I., Drolet, P. and Donati, F. (2009) Optimizing Pre-Oxygenation in Adults. 
Canadian Journal of Anesthesia, 56, 449-466. https://doi.org/10.1007/s12630-009-9084-Z

[2] Tang, L., Li, S., Huang, S., Ma, H. and Wang, Z. (2011) Desaturation following Rapid Sequence Induction Using Succinylholine vs. Rocuronium in Overweight Patients. Acta Anesthesiologica Scandinavica, 55, 203-208. https://doi.org/10.1111/j.1399-6576.2010.02365.x

[3] Lebovic, S., Reich, D.L., Steinberg, L.G., Vela, F.P. and Silvay, G. (1992) Comparison of Propofol versus Ketamine for Anesthesia in Paediatric Patients Undergoing Cardiac Catheterization. Anesthesia \& Analgesia, 74, 490-494.

https://doi.org/10.1213/00000539-199204000-00003

[4] Kirkwood, B.R. and Sterne, J.A.C. (2003) Essential Medical Statistics. 2nd Edition, Blackwell Science, Malden, $501 \mathrm{p}$.

[5] American Society of Anesthesiologists (2003) Practice Guidelines for Management of the Difficult Airway. An Update Report by the American Society of Anesthesiologists Task Force on Management of the Difficult Airway. Anesthesiology, 98, 12691277. https://doi.org/10.1097/00000542-200305000-00032

[6] Lane, S., Saunders, D. and Schofield, A. (2005) A Prospective, Randomised Controlled Trial Comparing the Efficacy of Preoxygenation in the $20^{\circ}$ Head-Up vs Supine Position. Anesthesia, 60, 1064-1067. https://doi.org/10.1111/j.1365-2044.2005.04374.x

[7] Nimmagadda, U. (2001) Preoxygenation with Tidal Volume and Deep Breathing Techniques: Impact of Duration of Breathing and Fresh Gas Flow. Anesthesia \& Analgesia, 92, 1337-1341. https://doi.org/10.1097/00000539-200105000-00049

[8] World Health Organization (2011) Patient Safety. Alliance for Better Health.

[9] Baraka, A. and Ramez, S.M. (2007) Pre-Oxygenation. In: Hagberg, C.A., Ed., Benumof s Airway Management: Principles and Practice, 2nd Edition, Mosby, Philadelphia, PA, 0196-0644. 